\title{
Studying the various Social Media Marketing Metrics for Indian SMEs
}

\author{
P. C. Jha \\ Department of Operational \\ Research, Faculty of Mathematical \\ Sciences, University of Delhi \\ Delhi, India
}

\author{
Remica Aggarwal \\ School of Business, University of \\ Petroleum \& Energy Studies, \\ Dehradun, India
}

\author{
P. K. Kapur \\ Amity Center of Interdisciplinary \\ Research, \\ Amity University, Noida, India
}

\begin{abstract}
Social media or digital media has gradually emerged from just being a personal, consumer oriented paradigm to something that has huge impact on businesses . The scenario is even more overwhelming in developing countries such as India with website such as Facebook and Youtube capturing a large users base. The success and consequently the positive influence of the social media over the business growth can be measure with the help of various metrics. Present research work focuses on exploring and studying some of the popular social media marketing metrics for Indian SMEs.
\end{abstract}

\section{Keywords}

Social media metrics; Digital marketing ; Small medium enterprises ; developing countries

\section{INTRODUCTION}

As Facebook's second largest market, yielding just 6 million users to the US, India is definitely one of the most interesting economies to analyze1. Today 34.8 percent of India's population is using the Internet, and this figure is about to reach 55 percent or more by 2025 . Amongst the most popular social media channels being Facebook, Youtube , Linkedin and twitter for sharig personal and professional photographs , downloading and uploading videos, uploading various commercial and educational content and for blogging respectively. Instagram is catching up too through its recently launched 'Shop Now' option that offers online store functionality within the app. Instagram has good CTA buttons, so that probably helps people get higher conversion rates from the platform. Other social media platforms ( a.k.a social networking platforms and collaborative platforms ) include Pinterest, Google+, Houzz , Architizer , Google analytics, Hootsuite etc. For example , Google Analytics pings the Google servers every time your page is visited and keeps a note of traffic sources and what actions they took on your website. HootSuite is a social media dashboard that allows businesses, organizations, and individuals to monitor, manage, and schedule all their social media marketing activity. It is commonly used to view and schedule the social media content updates including Facebook and Twitter. Now days, organizations are also hiring digital marketing firms to increase the customers visits and hence business growth. A usual digital marketing firm assignment starts with planning a custom web presence strategy for the desired business customer. This is done through website design and development, mobile development, social media account creation and branding. It then position the brand through pay per click advertising and search engine optimization tactics through pay per click advertising and search engine optimization tactics that include on page and off page SEO that are google approved. After that they promote the brand using an inbound marketing strategy or content marketing strategy to help the clients accomplish their marketing goals. This is majorly done through blogging, video production , call to actions, landing pages and free educational offers . Finally they protect the brand's web presence with a reputation management program that monitors the social media and on line reviews.

Although social media has accumulated quite many accolades to its credit, it is also true that it is not everyone 's cup of tea and not everyone see a positive ROI . Despite the fact that 77 percent of marketers are using at least one social media channel to market their business, only 48 percent of businesses claim to see any ROI whatsoever ${ }^{1}$. There are many reasons for this discrepancy. Possible could be that it takes significant time and effort to be successful. You need to have thorough understanding of your target market and you need to be active consistently before you see a return on the investment . Social media ROI depends on other marketing channels and a positive ROI is hard to get . Social media ads can yield a positive ROI in their own right, but they're inherently costlier than purely organic strategies. Amongst other marketing challenges includes the budgetary constraint followed by the misinformation and lack of innovation in marketing and content-creation, quality lead generation and attracting talent are some of the additional challenges ${ }^{2}$. If Indian companies are targeting foreign markets, language barrier could be another challenge . For example, There are certain phrases that US companies use more frequently such as 'customize' whereas UK, it is replaced by the word 'bespoke,' as it is more common in the UK. Tools like SEMrush that do keyword analysis can give you insights into these differences. So you need to understand the mindset of your local market in order to develop the web content. Further you need to have people on your team who have a marketing background, who can research the industry, the market, product visibility, demographics or culture-specific trends before you enter a foreign market. Of course, all this information can't be found in one place, and you have to consult an industry journal or a research organization. There are some places that marketers should go to: Social Samosa and Lighthouse Insights. These two websites cover the majority of digital marketing campaigns run in India and provide a detailed overview of how they perform, what works and what doesn't, as well as what is good and what is bad.

Present paper identify various metrics for measuring or assessing the performance of social media marketing and its influence on the growth of SME s in developing countries like India . These metrics have been discussed in section 2 . Managerial implications are provided in section 3 . 


\section{VARIOUS SOCIAL MEDIA MARKETING METRICS}

Usage of social media raises barriers to entry and consequently makes it difficult for new entrants to compete. This section reviews some of the barriers to social media marketing in Indian industrial scenario. Authors have made use of keywords search through google, use of Mendeley software etc. Keywords such as "social media marketing", " barriers to social media marketing ", "digital marketing", " barriers to digital marketing in India" etc. have been used. Major metrics ${ }^{2}$ considered are as follows:

\subsection{Cost per Lead}

If your website is collecting leads for your sales team to "close," you need to know how much you're paying for each lead. If the cost of each lead is more than what you produce by closing leads, that is indicative of a backward return on investment.

\subsection{Lead Close Rate}

How do you track your lead closes? An organization has to make sure that they are keeping an eye on the lead close rate so you can check that against the leads being generated. This will help you ensure your digital marketing efforts are delivering leads profitably. This information is also helpful to use as a control against new digital marketing efforts. If you suddenly get an influx of new leads but you find they close at a lower rate, then you may need to adjust your targeting efforts.

\subsection{Cost per Acquisition}

This can be obtained by dividing your marketing costs by the number of sales generated.

\subsection{Average Order Value}

While you want to see the number of your orders increase, paying attention to the value of the average ticket can reap significant rewards. A small increase in average order value can bring in thousands of dollars of new revenue, and can often be as simple as improving user experience and providing upsell opportunities.

\subsection{Conversion Rates by Channel}

An organization is particularly interested in knowing from where the traffic is coming from. Whether it's organic, paid, social media, or other avenues, this information tells us where the bulk of our customers are and/or where the marketing efforts are producing the most buzz. Let's say $\overline{75}$ percent of the traffic comes from organic marketing and 25 percent from PPC. But the PPC conversion rates are double that of organic. So it would be more profitable to invest in PPC. If you can increase PPC traffic to match organic, you've just doubled your ROI.

\subsection{Conversion Rates by Device}

Just like checking conversion rates by channel, you want to do the same by device.

\subsection{Landing Page Performance}

There are a lot of things to measure when it comes to the performance of your landing pages, bounce rates, CTR, conversions rates, conversion assists, etc. Look for any landing pages that aren't helping drive conversions. They are required to be fixed or eliminated, or the marketing driving the traffic needs to change.

\subsection{Blog Click-Through Rates}

Blogs are a great way to get traffic to your site. While blogs have notorious high bounce and exit rates, that doesn't mean you have to resign yourself to those ridiculously valueless numbers. Instead, use them to set goals for driving traffic from your blog to your main site. A small increase in blog click-throughs can provide valuable new business at almost no additional marketing costs.

\subsection{Customer Lifetime Value}

ROI of the marketing efforts can be easily understandable if the manager has a good idea about how the average customer will spend over their lifetime. For example, it costs about INR 500 to bring in a new sale or client . but the client make an initial purchase of INR 500 only. But what if you knew that the same customer will make a purchase of INR 500 every month for the next five years . in that situation the average lifetime value of the client become 5000INR .

\subsection{Brand or Non-Brand Factors}

Keep an eye on and differentiate between brand and nonbrand searches. Brand searches tend to have a higher clickthrough and conversion rates than non-brand because you're hitting people already familiar with you. By separating out this data, gives you additional insight into what is or isn't performing up to par.

\subsection{YoY comparisons}

Finally, when comparing data, it is advised to make year over year comparisons to get the true sense of how the campaign is improving.

\section{MANAGERIAL IMPLICATIONS AND CONCLUSIONS}

Social media marketing has many implications for marketers managers as well as research scholars. This section provides some of these implications [ 1-4].

- It is very important for the managers handling the social media content that the posts should be innovative, to the point and the kind of content that is appropriate for a certain channel and a certain stage of the buyer's journey.

- Further it is important to track the results through the built-in analytics tools like Facebook Insights, Google Tag Manager etc.

- It is always beneficial to opt for the reliable sources of information, whether it is a blog, a research or a course.

- By scaling social media follow-ups through involvement of genuine team of professionals and through use of all such tools that can bring new resurgence in the social media initiatives, managers can cope with the challenging situations. All they require timely and smart steps with genuine but persuasive outline for strategies developed to make best use of social media.

- 80 percent of traffic in India comes from the mobile devices, so in-app marketing and push notifications should be an essential part of any digital marketing strategy.

- Also the multi- channel digital marketing is becoming more popular and it is required that the managers should follow their customers across all 
different channels and provide a consistent experience across every one of them.

- When it comes to tools, each platform has its own ready-made analytics tool that is the best for that platform, such as Search Console for Google and Facebook Insights for Facebook, as well as iTunes Connect for the AppStore. It is therefore required that the managers make sure they get the most the accurate data possible out of these tools. If the data is inaccurate or if wrong metrics are being targeted, they eventually will land up in useless insights.

- Research Implications : The criteria developed above can be further studied for the possible interrelationship amongst them using ISM methodology. Interpretive structural modelling methodology or ISM developed by Warfield [5] is a known technique to map the relationships amongst the relevant elements as per decision maker's problems in a hierarchical manner.

\section{REFERENCES}

[1] Narayan, C. and Bhargava, M. 2012 . Online reputation killers and how to handle them. http:// www.businessworld.in/en/storypage/-/bw/online-reputation-killers-and-how-to-handle-them/518648.37489/ page/

[2] Chui, M., Dewhurst, M., Pollak, L. 2013 . Building the social enterprise. McKinsey \& Company. McKinsey Quarterly. http://www.mckinsey.com/insights/organization

[3] Divol, R, Edelman, D, Sarrazin, H. 2012. Demystifying social media. http://www.mckinsey.com/ insights/ marketing_sales/demystifying_social_media

[4] Singla , M.L. and Durga, A. 2015. How social media gives you competitive advantage, Indian Journal of Science and Technology, 8(S4), 90-95, ISSN (Print) : 0974-6846. ISSN (Online) : 0974-5645 DOI $10.17485 / \mathrm{IJST} / 2015 /$.

[5] Warfield, J.N. 1974. Developing interconnection matrices in structural modeling. IEEE Transactions on Systems, Man, and Cybernetics, (1), 81-87. 